\title{
Self-evaluation of Continuing Nursing Education Programs in Kirkuk Health Directorate Hospitals
}

\author{
Hussein M. Abdulfatah ${ }^{1}$ Salma K. Jeehad ${ }^{2}$ \\ ${ }^{1}$ Community Health Nurse Specialist, Kirkuk Health Directorate, \\ ${ }^{2}$ Professor, Community Health Nursing, College of Nursing, University of Babylon
}

\begin{abstract}
Objective(s): To self-evaluate Continuing Nursing Education Programs in Kirkuk Health Directorate Hospitals

Methodology: A descriptive design, using self-evaluation approach, is employed throughout the present study. A non-probability sample of (251) staff nurse who are recruited from Kirkuk Health Directorate Hospitals; Kirkuk General Hospital and Azady Hospital. A questionnaire is constructed for the purpose of the study which is comprised of (1) part, (6) aspects and (52) item. Content validity and internal consistency reliability are determined for the questionnaire through a pilot study. Data are collected through the use of the questionnaire and structured interview a means of data collection. Data are analyzed through the application of descriptive statistical data analysis approach of frequency, percentage, mean of scores, total scores and ranges.
\end{abstract}

Results: The study indicates that the overall self-evaluation of the Continuing Nursing Education Program in Kirkuk Health Directorate is poor for the majority of the subjects $(81.7 \%)$ and the mean of scores on items of aspects of self-evaluation of the Continuing Nursing Education Program is low on all items of these aspects.

Conclusion: The study concludes that overall self-evaluation of continuing nursing education program is depicted as poor relative to all aspects of continuing nursing education program of program goals, program planning, program performance, program operation and management, program outcomes and program effectiveness.

Recommendations: The study recommends that staff nurses should be seriously involved in the selfevaluation of the continuing nursing education programs for the reason that they are considered the consumers of such programs. Further research can be carried out on a large sample size, varied range scale of variables, large sample size and nation-wide continuing nursing education programs.

Key wards: Self-evaluation, Continuing Nursing Education Program, Kirkuk Health Directorate

\section{Introduction}

As professions go, nursing is pretty new. Until just more than 150 years ago when Florence Nightingale provided the building blocks for the field -- which included a training school and a nursing guidebook -anyone who found themselves in the role of caregiver could be considered a nurse. In fact, Nightingale once said that every person must at some time or other of the life becomes a nurse ${ }^{(1)}$.
Of course, that is back in the mid-19th century. Over the years, nursing has become a highly respected occupation that requires specific education and training. Not only that, but nurses also provide a wide spectrum of services to patients of all kinds (2).

Continuing education is the process that includes all the experiences after the initial training. Is characterized as the set of experiments after the initial training, allowing the worker to maintain, increase or improve 
your skills, so that this is consistent with the development of their responsibilities, characterizing, competence and individual attribute. It is a set of continuing education practices, aimed at developing the potential for a change in attitudes and behaviors in the cognitive, affective and psychomotor human being, the prospect of transforming their practice ${ }^{(3)}$.

Continuing nursing education (CNE) denotes to courses precisely for nursing professionals, intended at possession them up-to-date with the state-of-theart health knowledge. CNE safeguards professional growth and enables re-licensure and certification points in numerous countries. CNE also enlarges nurses' knowledge, skills and attitude while donating to their career development ${ }^{(4)}$.

Continuing education program is any postponement of opportunities for reading, study and training to any person and adult following their attainment of or removal from full time school and/or college program ${ }^{(5)}$.

Nursing is not just a set of specific skills, nor the nurse is only a person trained to perform specific tasks. Nursing is a profession. To be professional and act this way should be given careful consciously and based on their knowledge. Thus, a profession requires extensive education of those who practice and it is important to have a fundamental and theoretical body of knowledge and skills that generates defined standards. Hence the importance of continuing education becomes a key strategy for updating the professionals who are working in the field, bringing new concepts and knowledge relevant to a safer practice and conscious (3).

One of the delights of continuing nursing education is the amusing opportunity it offers for research. The very diversity of learners, content, programming potentials, and instructional strategies provide fertile Fields for investigation. Studies in continuing nursing education may discourse newly identified problems or provide new viewpoints on the study of acquainted problems. The instruments and techniques advanced to conduct these investigations are themselves a basis of possible claims in the delivery of continuing education, for example, in the refinement of needs assessment devices or evaluation strategies. Thus, reports of investigations should be examined on numerous levels: for their donations to knowledge in the field, for applicability to the solution of practical problems, and for the use of study instruments and methodologies for further investigations or in programming ${ }^{(6)}$.

Continuing nursing education (CNE) programs are designed to contribute to nurses' professional development by filling a gap in knowledge, skills, and practice. CNE is also the method through which nursing professionals improve their practice and keep up to date on the latest knowledge and advances in health care. It is important for nurse educators to evaluate the outcomes of CNE programs to make sure the gaps have been addressed. An outcome is defined as the end result of a learning activity measured by evaluation or change in practice $^{(7)}$.

Continuing nursing education and the application of new knowledge to practice are increasingly important means to improve patient care in today's health environment. The willingness and ability to transfer knowledge, skills, and attitudes are critical to improving patient outcomes ${ }^{(8)}$.

The evaluation of continuing nursing education is a vital part of improving the quality of educational activities. This evaluation defines if nurses meet the wanted learning outcomes and offers feedback on ways to advance the educational experiences that eventually progress patient care ${ }^{(6)}$.

Based on the early stated evidence, the present study ought to evaluate the Continuing Nursing Education Programs at hospitals in Kirkuk Health Directorate.

\section{Methodology}

A descriptive design is employed throughout the present study to self-evaluate continuing nursing education programs in Kirkuk Health Directorate from November $3^{\text {rd }} 2018$ to April $30^{\text {th }} 2020$.

After receiving the approval of the Council of Nursing College for the study and prior to data collection, proposal and questionnaire of the study have been submitted to the Ministry of Planning Central Statistical Organization and the Ministry of Health and Environment Kirkuk Health Directorate in order to obtain an official permission to carry out the study. The permission, after being granted, is presented to the hospitals to ensure the agreement and cooperation. 
The study is conducted at Kirkuk General Hospital and Azady Teaching Hospital in Kirkuk health Directorate. These settings are the designated site for data collection, because all of them are representing the classification of hospitals as general and specialized ones.

A purposive "nonprobability" sample of (251) staff nurse is selected for the present study. All staff nurses, who have participated in the study, have presented with consent form and they are asked to sign the form for their agreements for the participation in the study. All participants are introduced with the study objectives and they are presented with the opportunity of being aware of the study affairs. Such action has been implemented to protect the participants' human rights and facilitate access to them in order to gather the necessary data for the study.

The study instrument consists of the following:

Part I: Self-evaluation of Continuing Nursing Education Program

This part is comprised of the following:

\section{Program goals:}

This part is comprised of (7) items which are concerned with the program goals. It is evaluated as poor (7-12), fair (13-17) and good (18-21).

\section{Program Planning:}

This part is comprised of (6) items which are concerned with the program planning. It is evaluated as poor (7-12), fair (13-17) and good (18-21).

\section{Performance:}

This part is comprised of (7) items which are concerned with the program performance. It is evaluated as poor (10-17), fair (18-24) and good (25-30).

\section{Operation and Management:}

This part is comprised of (8) which are concerned with program's operation and management. It is evaluated as poor (10-17), fair (18-24) and good (25-30).

\section{Program Outcomes:}

This part is comprised of (10) item which are concerned with the program outcomes. It is evaluated as poor (10-17), fair (18-24) and good (25-30).

\section{Program Effectiveness:}

This part is comprised of (8) item which are concerned with the program effectiveness. It is evaluated as poor (8-13), fair (14-18) and good (19-24).

Each one of these aspects is evaluated based on the calculation of the total scores and ranges.

A pilot study is conducted for the determination of the study instrument validity and reliability for the period from February $12^{\text {th }}$ to March $7^{\text {th }} 2019$.

The content validity of questionnaire is determined by panel of (10) experts who are provided with copy of study instrument and are asked to review and evaluate the instrument for its content clarity and adequacy. Some items are excluded and others are added after taking all the comments and recommendations into consideration. So, the questionnaire is considered adequately valid measure after performing the modifications that are based on the experts' responses.

Internal consistency reliability of the questionnaire is determined through the use of split-half technique and the computation of Cronbach alpha correlation coefficient on responses of (20) staff nurse. The correlation coefficient is $(\mathrm{r}=0.85)$ which indicates that the questionnaire is adequately reliable measure.

Data are collected through the use of the study instrument and the structured interview technique as means of data collection for the period from March $10^{\text {th }}$ 2019 to May $8^{\text {th }} 2019$.

The data are analyzed through the use of descriptive statistical data analysis approach of frequency, percent, mean of scores, total scores and ranges. 


\section{Results}

Table (1): Overall Self-evaluation of the Continuing Nursing Education Program

\begin{tabular}{|l|l|l|l|l|l|}
\hline \multicolumn{2}{|l|}{$\begin{array}{l}\text { Poor } \\
(\mathbf{5 2 - 8 7})\end{array}$} & \multicolumn{2}{l|}{$\begin{array}{l}\text { Fair } \\
\mathbf{( 8 8 - 1 2 2})\end{array}$} & \multicolumn{3}{l|}{$\begin{array}{l}\text { Good } \\
(\mathbf{1 2 3 - 1 5 6 )}\end{array}$} \\
\hline F & $\%$ & F & $\%$ & F & $\%$ \\
\hline 205 & 81.7 & 43 & 17.1 & 3 & 1.2 \\
\hline
\end{tabular}

F: Frequencies, \%: Percentages

This table indicates that such overall self-evaluation of the Continuing Nursing Education Program in Kirkuk Health Directorate is poor for the majority of the subjects $(81.7 \%)$.

\section{Discussion}

Analysis of overall self-evaluation of the Continuing Nursing Education Program in Kirkuk Health Directorate has indicated that staff nurses have appraised such program as poor for the majority of them. Such finding provides empirical indication that the continuing nursing education program has experienced series of inadequacies with regard to all aspects of the program. Such self-evaluation is noticed in all the poor mean of scores on items of program goals, program planning, program performance, program operation and management, program outcomes and program effectiveness.

Continuing nursing education (CNE) has become essential for the assurance and improvement of quality patient care. CNE includes self-education and directed training activities designed to acquire new knowledge further to that which is acquired through the basic nursing education. It is a process that begins with the end of studies and lasts for the entire life of the individual. A descriptive correlational study investigates the motivating factors for participation of nurses in continuing nursing education (CNE) and their perceptions about the necessity for programs in CNE. The Participation Reasons Scale (PRS) is completed by (475) nurses working in three hospitals in Athens and the Peloponnese region and the socio-demographic data of participants are recorded. The study shows that the majority (62.3\%) of the sample showed positive perceptions and attitudes about CNE programs which are based on real needs. Subjects rated all five factors (dimensions) of the PRS as "moderately important" in high percentages, specifically: "Professional improvement and development" 98.9\%, "professional service" 91.8\%, “collegial learning and interaction" $82.6 \%$, "personal benefits and job security" 91.0\%, "professional commitment" 88.4\%. "Professional commitment" recorded the highest mean score (4.95 \pm 0.744$)$. "Professional improvement and development" correlated positively with "collegial learning and interaction" $(\mathrm{r}=0.229 ; \mathrm{p}<0.001)$ and "personal benefits and job security" $(\mathrm{r}=0.115 ; \mathrm{p}=0.015)$. The study concludes that motives and personal professional attitudes exert a significant effect on the participation of nurses in CNE programs ${ }^{(9)}$.

A cross-sectional study with (152) nurses in a public hospital in Pernambuco is carried out to analyze the opinions of nurses on a permanent education program, identifying reasons that influence adherence. The study findings depict that respondents have agreed that lifelong learning improves formation professional. The majority of participants has appreciated the methodology and approves three types of program: in practice simulation room; on the spot; and clinical meeting. The study has found to be essential to consider the opinion of nurses reporting workload after participating in training activities and who prefer to be consulted in advance about the subjects offered. Recognize and value the professional advice shows up relevant for to adopt measures aimed at increasing the effective entry into the program ${ }^{(10)}$. 


\section{Conclusion}

The study concludes that overall self-evaluation of continuing nursing education program is depicted as poor relative to all aspects of continuing nursing education program of program goals, program planning, program performance, program operation and management, program outcomes and program effectiveness.

\section{Financial disclosure}

There is no financial disclosure.

Conflict of Interest: None to declare.

Ethical Clearance: All experimental protocols were approved under the Kirkuk Health Directorate and all experiments were carried out in accordance with approved guidelines.

\section{References}

1. Sellers J. What are the Different Types of Nurses? Available at: https://health.howstuffworks.com/ medicine/healthcare/different-types-of-nurses.htm. 2019.

2. Santiago, A. Different Types and Roles of Nurses. 2019.

3. Barreto B. Tavares D. Brandão J. Gonçalves J. Valente G. and Ferreira F. Continuing Permanent Education as a Strategy for Managing of Nursing in the Unique Health System: An Integrative Review. Revista de Pesquisa: Cuidado é Fundamental Online. 2013; 5(3); 85-93.
4. Pacific Open Learning Health Net (POLHN). Continuing Nursing Education: Breaking the Barriers. Available at: https://polhn.org/blog/ continuing-nursing-education-breaking-barriers. 2018.

5. Saira R. Continuing Nursing Education. Education, Health and Medicine. Available at: https:// www.slideshare.net/riasaira/continuing-nursingeducation-26670550. 2013.

6. Wellings C. Gendek M. Gallagher S. Evaluating Continuing Nursing Education: A Qualitative Study of Intention to Change Practice and Perceived Barriers to Knowledge Translation. Journal for Nurses in Professional Development. 2017; 33(6):281-289.

7. Zupanc T. Development of an Outcome Measurement Plan for an Accredited Continuing Nursing Education Provider Unit. The Journal of Continuing Education in Nursing. 2016; 47(2): 8996.

8. McDonald B. Evaluating Continuing Nursing Education. Journal for Nurses in Professional Development. 2017; 33(6): E7-E8.

9. Kamariannaki D. Alikari V. Sachlas A. Stathoulis J. Fradelos C. and Zyga S. Motivations for the Participation of Nurses in Continuing Nursing Education Programs. Archives of Hellenic Medicine. 2017; 34(2):229-235

10. Neves G. Andreto L. Oliveira C. and Figueira M. Opinion of Nurses on Permanent Education in A Public Hospital. J Nurs. 2016; 10(5): 1625-34. 